\title{
A EXPERIÊNCIA ESTÉTICA COMO ACONTECIMENTO FORMATIVO ÉTICO
}

\section{BEAUTY EXPERIENCE AS EVENT ETHICAL FORMATION}

\author{
Clênio Lago* \\ Professor do Mestrado em Educação na Universidade do Oeste de Santa Catarina de \\ Joaçaba \\ Andressa Cristina Vani** \\ Professora de Artes na modalidade Educação de Jovens e Adultos (EJA) na unidade \\ do SESI-FIESC em São Miguel do Oeste
}

Resumo: Partimos do entendimento de que o ensino de arte é portador de possibilidades formativas, pois seu modo de ser originário originante é, essencialmente, o modo de ser do diálogo. Por isso, pergunta-se pela compreensão da relação estética e formação dos arte-educadores que atuam na SDR de São Miguel do Oeste/SC. As argumentações teóricas estão estruturadas no horizonte da Hermenêutica Filosófica que questiona a distinção estética e compreende o ser com temporalidade, o humano como obra em obra. As respostas da pesquisa empírica indicam compreensões pouco apuradas quanto à experiência estética em si e a relação desta com a formação, ao mesmo tempo que chamam para a experiência estética como formação ética. Conclui-se pela necessidade de uma formação de professores para além da distinção estética, no âmbito da compreensão profunda entre experiência estética e formação.

Palavras-chave: Ensino da Arte. Experiência Estética. Formação. Ética.

Abstract: We start from the understanding that the teaching of art is a carrier of formative possibilities because its original originating way of being is essentially the dialogue way of being. This is why the formation and aesthetic relationship of art

\footnotetext{
* Doutor em Educação pela Pontifícia Universidade Católica do Rio Grande do Sul; Mestre em Educação pela Universidade Federal de Santa Maria.

** Pós-graduanda do Curso de Arteterapia, Educação e Saúde da Universidade do Oeste de Santa Catarina de São Miguel do Oeste; Graduada em Artes Visuais - Licenciatura Plena na Área das Ciências das Humanidades pela Universidade do Oeste de Santa Catarina.
} 
teachers working in the São Miguel do Oeste/SC SDR's coverage are is questioned. The theoretical arguments are based on Philosophical Hermeneutics which questions the aesthetic distinctions and comprehend the being with temporality, the human as a work under construction. The answers of empirical research indicate understandings bit cleared on the aesthetic experience itself and its relationship with the formation. The answers also call the aesthetic experience as ethic formation. We conclude that a formation that goes beyond the aesthetic distinction and comprehend deeply the aesthetic experience and formation is needed.

Keywords: Art teaching. Aesthetic Experience. Formation. Ethical.

\section{CONSIDERAÇÕES INTRODUTÓRIAS}

Quando a sociedade vive um período de crise mais adensada, a educação recebe por inteiro as consequências da anomia e da perda de sentido. (HERMANN, 2005, p. 20).

Vivemos um tempo marcado pela crise paradigmática, em que não somente a ideia de verdade, como também os ideais educacionais entram em crise, além do próprio racionalismo clássico, em que a razão se constitui como o referencial à certeza e o emergir do paradigma estético. Ao mesmo tempo, é o momento em que a própria razão é radicalmente interpelada e passa a se colocar na escuta do outro, reconhecendo-o enquanto outro, conferindo novas perspectivas à formação, deixadas de lado no modo metafísico de pensar. Portanto, faz-se necessário refletir amplamente sobre o papel da arte na formação, na medida da emergência da esteticização do mundo da vida, do cotidiano das ações humanas. Suscita a revisão da própria compreensão de arte, da experiência estética e da própria ideia de formação, bem como da relação entre estética e formação, visto a profunda experiência de niilismo vivida atualmente nos mais variados campos, dentre eles, na educação, muitas vezes, gerando um aspecto catastrófico e reacionário.

Compreendemos que o ensino de Artes é portador de possibilidades formativas, pois seu modo de ser originário é essencialmente o modo de ser do diálogo em que a formação se constitui como um processo aberto, receptivo e inquiridor da ação mediante a livre articulação fruidora que os envolve na experiência temporal do acontecer humano. Por isso, abordaremos a experiência estética e sua relação com formação, com destaque especial para o contemporâneo e os desafios desse tempo à educação. Esta reflexão encontra guarida, à medida que a contemporaneidade se apresenta com os desafios da presença da diferença, do outro, da pluralidade, da inclusão, das transformações sociais e institucionais, com ruptura da ideia de verdade e ideais absolutos; com os desafios da 
efemeridade, da liquidez e, com isso, a necessidade de rever os valores, referenciais, ideais e métodos, a própria condição humana como temporalidade.

Inicialmente, pergunta-se: como a experiência estética e a relação desta para com a educação é compreendida pelos professores que atuam no ensino de artes na Educação Básica na região de abrangência da SDR de São Miguel do Oeste - SC?; Quais os desafios desse processo e se a forma como esta relação é compreendida se constitui em possíveis respostas aos desafios contemporâneos da educação, para depois perguntar sobre a relação entre experiência estética e formação ética. Dessa forma o estudo, efetivado no campo teórico efetivou-se igualmente a partir da colaboração espontânea de pedagogo e arte-educadores que atuam com o ensino de artes, na região de abrangência da SDR de São Miguel do Oeste - SC, (municípios de Barra Bonita, Belmonte, Descanso, Guaraciaba, Paraiso, Bandeirante, São Miguel do Oeste). Para o processo de coleta de dados aplicamos um questionário semiestruturado aos professores estaduais e municipais, totalizando a participação de vinte e cinco professores.

Mas como forma de respostas à premência dos desafios postos à compreensão profunda da experiência estética na formação nos processos pedagógicos refletimos, por força dos desafios indicados pelos arte-educadores, a respeito da formação como acontecimento ético pela experiência estética, inicialmente valendo-nos dos indicativos colhidos com os professores, e depois ascendendo à reflexão sobre experiência estética e formação como acontecimento ético.

\subsection{OS DESAFIOS DA RELAÇÃO EXPERIÊNCIA ESTÉTICA E FORMAÇÃO COMO UM DESAFIO ÉTICO}

Os dados empíricos aqui apresentados foram adquiridos com base na colaboração espontânea de 25 educadores e arte-educadores que atuam em escolas públicas (municipais e estaduais) com o ensino de Artes na região de abrangência da SDR de São Miguel do Oeste - SC. Dizem respeito às percepções destes sobre os desafios do ensino de Artes, e os apresentamos como forma de indicar o necessário debate entre ética e estética, partindo da experiência estética como uma forma do acontecer ético e configuração, reconfiguração dos valores. Portanto, a experiência estética como um acontecimento importante na formação das subjetividades.

Quanto à compreensão da relação entre experiência estética e formação por parte dos pedagogos e arte-educadores constitui-se um mapa plural, que, no quadro geral, é no mínimo inquiridor das finalidades e horizontes da experiência estética nos processos de formação via ensino de artes. Ainda marcados, seja pela pouca compre- 
ensão da relação entre experiência estética e formação, seja pelo lugar histórico ocupado pela arte, estando "[...] associada ao culto da aparência, à superficialidade [...]" (HERMANN, 2005, p. 12). Ainda marcados por questões históricas, oscilando entre o esteticismo e a tradição estética, destacam a importância da experiência estética nos processos de formação humana.

[...] a experiência estética é muito importante para a formação no processo de ensino e aprendizagem, evidencia o ser humano em seu todo, razão e emoção. Ao contemplar algo é possível que surjam emoções de agrado, desagrado, repulsa, tristeza, prazer, beleza, mas quando se cria algo, essa experiência é como um meio de comunicação, busca-se expressar ali, as emoções, com o desejo de que, quem posteriormente for contemplar, possa igualmente vivenciar emoções [...] (Professor F., 2013) (informação verbal).

Conforme as considerações de $\mathrm{PF}^{1}$, a experiência estética é compreendida à medida que evidencia o ser humano em seu todo razão e emoção, ou seja, permitir este a sentir-se em seu todo, possibilitando assim que o processo de ensino-aprendizagem aconteça de forma integral e não centrado apenas no sensível ou no racional como forma metafísica de pensar. A experiência estética possibilita o conhecimento daquilo que é excluído pela lógica do conceito, criando novas compreensões de mundo (HERMANN, 2005), por meio do impulso lúdico (SCHILLER, 1991), quando reconhece o verdadeiro valor da arte para com a formação da humanidade, a se efetivar no processo de conjugação dos impulsos formal e sensível, no impulso lúdico da criação como autoformação.

Ao mesmo tempo que a arte é vista como grande possibilidade formadora por meio da experiência estética, os desafios de educar na contemporaneidade são indicativos e uma maior reflexão, pois cerca de $68 \%$ dos pesquisados afirmam que o desafio da educação, sentido na falta de valores éticos e morais preestabelecidos pela família e sociedade, dificultam a convivência humana e o processo de ensino-aprendizagem. Para estes, a arte pode contribuir uma vez que propõe a reflexão destas questões de forma contextualizada e desenvolve ações que despertam a criatividade e a sensibilidade. Já 14\% ressaltam em suas compreensões de que o desafio é acompanhar o avanço da tecnologia e pensam ser a arte uma possibilidade para suprir as carências da sociedade mediante seus matizes. Outros $7 \%$ pensam ser o desafio de formar cidadãos que tenham uma visão de mundo. E, para estes, a arte pode auxiliar a quebrar modelos esteticamente padronizados. Ainda, 11\% não responderam esta indagação. No sentido de chamar a atenção para os desafios indicamos algumas manifestações dos pedagogos e arte-educadores que atuam no ensino de Artes da SDR de São Miguel do Oeste/SC. 
A educação hoje vive um momento extremamente delicado. A família deixou de fazer seu papel e de certa forma sobrecarregou a escola o que antes era dever da família, hoje a escola é responsável. Existe uma crise de valores morais, a violência e uma guerra desleal por meio das mídias. É um contexto perturbador. A arte surge em meio a isso trazendo sensibilidade, percepção e olhares diferenciados que mediante esse momento, fazem a diferença a alguns. (Professor K, 2013).

Tenho a sensação que estamos presos a algo que sabemos que não funciona mais, mas não nos permitimos experimentar. $\mathrm{E}$ quando comento, com colegas, que os educandos (muitos deles) não gostam muito de pensar, ou evitam ao máximo qualquer esforço nesse sentido, acabo por olhar para mim: até que ponto eu quero pensar? $\mathrm{Ou}$, tenho tempo para isso? Uma grande lógica está conseguindo nos fazer mera força de trabalho. E isso me frustra. Talvez a arte seja minha ponte, e umas das poucas formas que consigo visualizar, para buscarmos uma maneira diferente de sentirmos o que nos cerca. A relação com o próprio corpo, com os outros, com o ambiente, pode ser experimentado pela arte. Ela possibilita essa reflexão, seja pela historia ou pelas vivências que podem surgir dessa reflexão (Professor X, 2013).

A educação vive muitos desafios, desde o da carência educacional, limites, violências ate o avanço mais célebre da tecnologia. Acredito ser a arte um instrumento importantíssimo para suprir parte dessas carências através de seus múltiplos matizes, pois podemos nos valer de propostas que oportunizam o educando a se reorganizar, a se reconhecer como ser único e fundamental para o equilíbrio do todo, através do teatro, das mímicas, das poesias, das danças e das artes plásticas (Professor Z, 2013) (informações verbais).

Mediante as compreensões ressaltadas percebem-se dois aspectos relevantes no que diz respeito aos desafios de educar na contemporaneidade, sendo a falta de paradigmas e/ou valores predefinidos pela família e o desafio de acompanhar a inserção das novas tecnologias na sala de aula, ao mesmo tempo que se percebe insatisfação ao método tradicional que clama por "atualização".

Concomitantemente destaca-se que, de alguma forma, o ensino de Artes é chamado a contribuir, a gerar novas perspectivas, como uma condição à humanidade. Mas um indicativo é correto, o de que as transformações significativas, pelas quais a sociedade contemporânea está passando nas últimas décadas, vêm questionando os referenciais tradicionais, ao mesmo tempo que a realidade se revela em perspectivas nos mais variados âmbitos da existência humana, trazendo desafios, sobremaneira à educação. Segundo Goergen (2012, p. 166-167),

Vivemos, é certo, novos tempos, seja no campo do conhecimento, da ética ou da estética. São rejeitadas as grandes narrativas, 
as tradições epistemológicas, a centralidade do sujeito, a história como processo unidirecional em permanente progresso.

Quanto à estética é a crise da experiência estética, estruturada no âmbito da distinção estética desde a perspectiva dos referenciais tidos como estruturais a uma obra de arte: os modos tradicionais de compreender a arte, a estética e experiência estética e sua relação com a formação. Nas palavras de Paviani (2011, p. 37): “[...] a crise ética atual é igualmente uma crise estética"2 situação em que "não são apenas as artes que lutam pela sua sobrevivência; é o próprio projeto de uma estética no limiar tenso entre as artes e a filosofia que se vê posto em xeque." (FLICKINGER, 2011, p. 509). Sintetiza Goergen (2012, p. 161): “O que, de fato, está em crise é o projeto modelo de conhecimento e seu sentido humano." É nesse caminho que revisamos a relação entre estética e formação e nesta relação o significado da experiência estética.

\section{ESTÉTICA E FORMAÇÃO}

Bayer (1995, p. 13) coloca que “A palavra estética só apareceu no século XVIII, sob a pena de Baumgarten (1714-1762) [...] significava apenas teoria da sensibilidade, de acordo com a etimologia da palavra grega: aisthesis." Surgiu como uma ciência específica para o conhecimento sensível em que o "[...] o gosto está atrelado ao bom gosto e, ainda, à grandeza, à verdade, à clareza e naturalmente à perfeição" (MEDEIROS, 2005, p. 38). Desse modo, a estética marca seu surgimento como uma disciplina filosófica, ao lado da lógica, da metafísica e da ética, objetivando a compreensão do belo (HERMANN, 2005). A partir da crise da modernidade, a estética institui-se no lugar do paradigma racional, como o paradigma dominante, acenando que tudo, inclusive a verdade, precisa ser esteticamente apresentada para ser verdade. Mas

"uma esteticização total leva em direção ao seu oposto. Onde tudo é belo, nada mais é belo; estimulação ininterrupta conduz ao embotamento; esteticização vira anestetização." (WELSCH, 1995, p. 18, grifo do autor). A sensibilidade fica cega, perde sua capacidade crítica, tornando-se incapaz de perceber os princípios desviantes, ao que Gadamer (2005) caracteriza como distinção estética.

A estética esteve sempre ligada à reflexão filosófica, à arte e à sociedade, em primeiro momento buscava-se a compreensão do belo. No campo da filosofia clássica a estética recebeu suas definições por meio de alguns filósofos, como Platão, o qual acreditava que o belo era uma via de acesso ao mundo das ideias. Por isso, em sua obra, A República, apresenta o ideal de homem racional, aquele capaz de sair da caverna, do mundo das sombras para o mundo das luzes, do mundo sensível ao racio- 
nal, pois “"...] o mundo sensível não produz o verdadeiro conhecimento, ao contrário, a eikasía é o primeiro grau do conhecimento e se refere a uma cópia ou simulacro da coisa sensível.” (HERMANN, 2005, p. 12). Nesse sentido, a experiência estética para Platão, como a estética não tinha valor em si, mas na ideia, “[...] o supremo escalão da dialéctica que a ela conduziu, fica subordinado à razão. Mas a ideia em si, para ser percebida, não exige apenas um processo intelectual, mas um salto último. É esse elemento irracional, intuitivo, visionário que permite à beleza ter a sua manifestação na aparência” (BAYER, 1995, p. 40), como manifestação da ideia.

$\mathrm{Na}$ perspectiva platônica, “[...] quem se guia pelas aparências estaria impossibilitado de ver a realidade como ela é, por isso, seria escravo. [...] Vive no mundo da opinião e não conhece a verdade." (LAGO, 2011, p. 32). O conhecimento adquirido pelos sentidos seria ilusório e o belo era visto como a representação da natureza em que remete à ideia, ao belo ideal e aos absolutos, constituindo o lugar histórico ocupado pelo ensino de Artes, como algo sem muito valor, ou com pouco valor em si, frente às demais disciplinas, cabendo-lhes a bela representação. Não tem autonomia própria. Contudo, não podemos desconsiderar a ressalva platônica de que os sentidos nos enganam, pois esta ressalva nos permite sempre mais avaliarmos nossas percepções, impressões como um filtro, mesmo que tenhamos que rever a teoria das ideias, o que indica que o belo não é qualquer expressão, mas a expressão que em última instância suscita e representa a ideia de bem. Mas, o limite está em não conceber o sensível como capaz de perceber o real pelos flashes que nos chegam, como verdade temporal, e se possibilitam não têm autonomia de juízo.

Já Aristóteles, discípulo de Platão, considerado uma importante referência da concretude contrariava seu mestre, afirmando que "[...] as Ideias não estão no além, elas existem na realidade. [...] As Ideias não são, portanto, a única realidade; o mundo sensível é igualmente real e o indivíduo é a primeira e a mais alta realidade ou substância." (JIMENEZ, 2000, p. 215). Nestes termos compreende-se que não existe um conceito de artista em si como pura definição, mas um potencial de vir a ser artista pelo exercício mimético, pois Aristóteles enfatiza a relação entre imagem e objeto de modo a evidenciar a capacidade mimética como algo produtivo e não apenas como representação fiel do objeto como em Platão. Dessa maneira, “[...] a educação, para Aristóteles, é a mímesis da energia humana. Em Platão, a natureza é mímesis do mundo das ideias que, por sua vez, se reproduz na atividade humana. Por isso as artes imitam a natureza." (TREVISAN, 2000, p. 60, grifo nosso). Apesar das diferenças entre os dois filósofos, as categorias estéticas, aqui, referem-se ao objeto, enquanto ideal e real. Na visão clássica, é "[...] o objeto, que desencadeia, por sua beleza, o impulso mimético." (LONGHI, 
2005, p. 397). Mas, não podemos perder de vista que este debate entre Platão e Aristóteles ainda dará bons frutos, à medida que perpassado pela emergência da diversidade, encontrando nova formulação na Hermenêutica Filosófica ${ }^{3}$.

Desde então, até à modernidade a postura platônica predominou como pano de fundo, quando no século das luzes as discussões envolvendo questões estéticas em torno da experiência estética alcançam maior autonomia nos seus princípios e critérios, ao questionar os aspectos objetivos transcendentais da obra de arte com base na centralidade do sujeito transcendental mediante as três críticas kantianas. Destaque especial para a Crítica da faculdade do juízo (2008), na qual Kant apresenta a experiência estética não mais apenas como experiência do belo, mas também como experiência do sublime: a primeira como representação afins da natureza possível pela percepção da conformidade afins entre objeto e imaginação; a segunda como experiência do estranhamento, de negação. Enquanto o belo constitui-se num sentimento de afirmação e promoção da identidade existente, o sublime consiste num prazer que não surge indiretamente, pois se estabelece na disposição de espírito.

Surge com Kant a ideia de autonomia, ou seja, que pelo entendimento alcançado pela razão pura o ser humano se constitui como sujeito transcendental que possui a capacidade de compreender a verdade em si pela subjetividade e o belo como afins com a natureza, como algo por si. Diante disso, para Kant “o julgamento sobre o belo é algo próprio de cada um, subjetivo, mas, ao mesmo tempo, universal e objetivo, não manifesta uma mera preferência, mas tem também um assentimento intersubjetivo" (KANT apud HERMANN, 2005, p. 36), como transcendental. O belo refere-se agora não mais às condições transcendentais do objeto, mas às do sujeito, por isso, na modernidade, ocorre um deslocamento do objeto para o sujeito que percebe, como harmonia das faculdades. Assim,

[...] uma bela obra de arte deve parecer ter saído da natureza. Ela deve dissimular tudo o que se aproxima de uma finalidade ou de um interesse e responder às condições do belo natural [...]. Ela pode satisfazer, causar prazer, mostrar que resulta do livre jogo da imaginação e do entendimento, que seu único e fim é a harmonia das faculdades, [...] e suscitar um assentimento comunicável e universal, sem todavia basear-se em conceitos. (JIMENEZ, 2000, p. 132).

Nesse contexto, "[...] o estético não resulta da cognição, mas se relaciona com a transmodelagem dos objetos, que envolve todos os sentidos do sujeito, que competem entre si e forçam o sujeito a lidar com as novas possibilidades geradas na experiência” (HERMANN, 2005, p. 42), num livre jogo entre imaginação e entendi- 
mento, ao que Schiller (1991) chama de impulso lúdico, efetivado a partir da experiência do belo e do sublime.

Contudo, será com Schiller (1759-1808) que a estética conquista autonomia quando se interpõe tanto contra o rígido racionalismo quanto com o naturalismo, objetivando o equilíbrio da razão e emoção no jogo, entre razão e natureza como impulso lúdico. Segundo Schiller (1991, p. 39), “[...] para resolver o problema político é necessário caminhar através do estético, pois é pela beleza que se vai à liberdade.” Isso porque o homem pode, por duas maneiras, viver em oposição a si mesmo, tanto pelo impulso sensível, quanto seguindo o impulso formal.

Como selvagem, quando seus sentimentos imperam sobre seus princípios, ou como bárbaro, quando seus princípios destroem seus sentimentos. O selvagem despreza a arte e reconhece a natureza como sua senhora irrestrita; o bárbaro escarnece e desonra a natureza, mas continua sendo escravo de seu escravo por um modo frequentemente mais desprezível que o selvagem. $\mathrm{O}$ homem bem formado faz da natureza sua amiga e respeita sua liberdade, na medida em que apenas põe rédeas a seu arbítrio. (SCHILLER, 1991, p. 46).

Schiller, na obra $A$ educação estética da humanidade aposta no impulso lúdico como o impulso capaz de, por meio da arte, superar as fragmentações da modernidade e do egoísmo, a possibilidade de harmonizar os impulsos contraditórios. "O impulso do jogo ou impulso lúdico conciliaria a permanência na transformação, a sensibilidade e a receptividade dos sentidos com a força criadora da razão" (HERMANN, 2005, p. 68), possibilitando ao homem sair do estado de necessidade para um estado de liberdade. Assim, quando o homem interior é uno consigo mesmo salva tanto o formal quanto o sensível. Ou seja, o homem somente encontra sua plenitude enquanto joga. Em meio aos desafios dos dois princípios estéticos, o apolíneo e o dionisíaco (debate proposto por Nietzsche), a proposta de Schiller constitui-se numa plausível tentativa de conduzir a humanidade em sua formação integral por meio do impulso lúdico, embora, ainda preso ao subjetivismo. Mas ganha novos contornos no debate contemporâneo com a emergência da diversidade e seus desafios.

Ultrapassando o subjetivismo e apoiado nas proposições intersubjetivas postuladas por Hegel e perpassadas pelas provocações nietzscheanas, a estética com Gadamer (2005) ganha nova configuração e, com isso, também a relação com a formação, especialmente ao propor o jogo intersubjetivo como condição à humanidade, pois "sem essa abertura mútua, tampouco pode existir verdadeiro vínculo humano. A pertença mútua significa sempre e ao mesmo tempo poder ouvir uns aos outros." (GADAMER, 2005, p. 472). Exige o reconhecimento de que o outro, a tradição, o eu, 
o presente têm algo a dizer, ao mesmo tempo que vão se constituindo na multirreferencialidade. Mais do que isso, que nenhum indivíduo, em sua subjetividade, contém a verdade, senão que a verdade emerge no jogo, como histórica, o que requer " [...] a capacidade constante de voltar ao diálogo, [...] de ouvir o outro, parece-me ser a verdadeira elevação do homem à sua humanidade" (GADAMER, 2004, p. 251) de refazer-se. Ou seja, essa capacidade de efetivar-se no acontecer do ser como temporalidade pelo reconhecimento é possível de efetivação via diálogo compreendido, como um jogo de perguntas e respostas como experiência articulada entre o belo e o sublime, respectivamente como resposta e como pergunta. Enquanto tal, o jogo é o modo de ser da experiência estética em sua dimensão ontológica, como acontecer temporal. Constitui o próprio acontecimento.

A mútua referencialidade, o mútuo reconhecimento exige ultrapassar a subjetividade de cada jogador, num jogar e ser jogado que ganha vida própria, liberando o ser como devir, como acontecer originário originante. Assim também no encontro com uma obra, com um texto, como criação. Nesse sentido,

$\mathrm{O}$ artista é a origem da obra. A obra é a origem do artista. Nenhum é sem o outro. Do mesmo modo também nenhum dos dois porta sozinho o outro. Artista e obra são em-si e em sua mútua referência através de um terceiro, que é o primeiro, ou seja, através daquilo a partir de onde o artista e obra de arte têm seu nome, através da arte (HEIDEGGER, 2010, p. 37).

E, a exemplo do originário da obra de arte em que artista e obra são em-si, em sua mútua referência com um acontecer originário originante, na educação professor e aluno, ensino-aprendizagem, também o são elementos do jogo educativo que só tem sentido enquanto jogo, relação a partir da qual a formação ganha sua definição como autoformação. Assim, a experiência estética promove a formação como autoformação, uma vez que possibilita a experiência profunda de si, de quem a realiza, na relação consigo, com o outro e com o mundo como experiência ontológica produtiva, constitutiva do ser, da realidade em devir, como um encontra-se como um sair, como autocriação. E autoformação, autocriação e acontecimento não direcionável. Esse é o medo.

Para Gadamer, significa que, quem entra em jogo com a obra, com o outro, com o ser-aí como pré-sença é convocado ao ser em sua dimensão mais autêntica, pois a plenitude da experiência estética como autoformação libera o ser para ser em devir. Esta estética autêntica somente é possível no jogo intersubjetivo que ocorre com o viger do outro e do eu como abertura mútua, em situações não totalmente controláveis. Por isso, Gadamer (2005, p. 461) indica a 
[...] a experiência se instaura como um acontecer que não tem dono e que a importância particular dessa ou daquela observação como tal não é decisiva para sua instauração, mas que tudo acaba se ordenando de um modo que não pode ser compreendido. A imagem mantém essa peculiar abertura onde se adquire a experiência, $[\ldots]$ esta continua válida até que apareça outra experiência nova.

É na experiência profunda que fazemos com a obra, entre nós que pode se efetivar a formação como autoformação, na sua mais alta acepção. Por isso, uma aula apenas reprodutiva não resulta em formação, mas instrumentação e uma aula apenas solta perde o sentido. Contudo, ao que Gadamer (2005, p. 137, grifo do autor) chama de distinção estética?

A “distinção estética" atua como consciência estética, produz para si mesma uma existência exterior própria. Comprova sua produtividade na medida em que prepara, para a similitude os seus próprios lugares, a "biblioteca universal" no âmbito da literatura, o museu ou teatro permanente, a sala de concertos etc. Deve-se distinguir claramente daquilo que é mais antigo.

Consciência estética como essa consciência que se abstrai de tudo, até mesmo de si é o produto da distinção estética. Portanto, a distinção estética constitui a perda do fenômeno estético pela fragmentação entre sujeito e objeto, entre obra e observador, à media que inviabiliza a experiência estética e impede a consciência como acontecimento temporal, como temporalidade. É uma espécie de instrumentalização da arte, pois esvazia a experiência estética de seu poder transformador ao querer direcionar os processos. Se a distinção estética se constituiu pela fragmentação, por outro lado onde tudo se confunde não há mais experiência estética. Como compreender a arte contemporânea e a experiência estética e a relação com a formação.

\subsection{A ARTE CONTEMPORÂNEA}

Se tudo se confunde pela ausência de limites entre a arte a vida, a experiência estética perde a força de ser um contraponto às convenções do cotidiano e às certezas confiáveis. (HERMANN, 2011, p. 441).

Ao que pesa depois da reflexão acerca da relação entre experiência estética e formação em seus aspectos históricos, considerando as transformações ocorridas nos últimos anos, tais como a crise de valores, o empobrecimento da experiência, a ausência de verdades absolutas, a esteticização do mundo da vida em que estética vira 
anestetização (WELSCH, 1995), como compreender a relação experiência estética e formação sem que se caia na distinção estética e que a experiência estética se constitui como um sentir a obra contra um entender a obra em meio aos desafios do mundo contemporâneo? O que é obra de arte? O que significa a obra de arte, a estética e a experiência estética neste contexto por muitos, anunciado como pós-modernidade ou mesmo como hipermodernidade? As palavras de Oliveira (2011, p. 411) são elucidativas, pois

[...] um fundamento atemporal, último, significa a fuga do ser humano de sua própria historicidade, portanto que a ideia de uma verdade absoluta se origina do recalque ou do esquecimento da própria temporalidade.

Por outro lado, o questionamento posto por Oliveira indica que o puro acontecer cai no relativismo, podendo a humanidade perder-se tanto pelo viés do dogmatismo quanto pelo do relativismo. A obra de arte possui valor em si e como presença (GADAMER, 2005). É, ao mesmo tempo, em-si e energia: acontecimento, temporalidade. Assim, a experiência estética é acontecimento, seja pelo instante formativo da criação, seja pelo inesperado que provoca na contemplação, seja enquanto percepção, à medida que se instala como presença fluida. Liberada das pré-formatações, a arte contemporânea, como ser-aí acontecendo articula livremente os impulsos formais e sensíveis, de forma circunstancial, como temporalidade. Somente se constitui em sentido à medida que se configura estruturalmente, mesmo que de forma fugaz. Do contrário não consegue ser. Por isso, é temporalidade, é obra sendo em acontecimento, pois coloca em jogo os referenciais tidos como atemporais, uma vez que também é colocada em jogo por esses. É temporalidade porque não é nem pura permanência e nem pura mudança a provocar transformação em configuração ${ }^{4}$. Assim pergunta-se: Qual é o papel da arte contemporânea? Poderíamos, imediatamente, elencar algumas possíveis respostas, seja representar o cotidiano, seja provocar estranhamentos, ouvir o ser e provocar o devir, ou simplesmente anarquista, desconstrutiva.

Mas uma resposta mais consistente a essa pergunta faz emergir outra mais abrangente: O que é contemporâneo? Para tal, valemo-nos das considerações de Agamben (2009, p. 59), quando define que a contemporaneidade "[...] é uma singular relação com o próprio tempo, que adere a este e, ao mesmo tempo, dele toma distâncias; mais precisamente, essa é a relação com o tempo que a este adere através de uma dissociação e um anacronismo." O indicativo filosófico de Agamben (2009) é de que um contemporâneo é aquele que estabelece certa relação de proximidade e de distan- 
ciamento para com seu tempo, uma relação de reconhecimento, não ficando apenas jogado no tempo, nem apenas como pura expressão do tempo. Assim,

Pertence verdadeiramente ao seu tempo, é verdadeiramente contemporâneo, aquele que não coincide perfeitamente com este, nem está adequado às suas pretensões e é, portanto, nesse sentido, inatural; mas, exatamente por isso, exatamente através desse deslocamento e desse anacronismo, ele é capaz, mais do que os outros, de perceber e apreender o seu tempo. (AGAMBEN, 2009, p. 58).

Entretanto, é preciso compreender ${ }^{5}$ os propósitos de sua época para não aderir totalmente ao que ela propõe como forma de "enquadrar" o sujeito às suas pretensões. Nesse sentido, "pode dizer-se contemporâneo apenas quem não se deixa cegar pelas luzes do século e consegue entrever nessas a parte da sombra, a sua íntima obscuridade. [...] Contemporâneo é aquele que recebe em pleno rosto o facho de trevas que provem seu tempo." (AGAMBEN, 2009, p. 63-64). Um exemplo dessa sombra é o modismo, pois percebemos que a moda ou tendências do momento são hoje uma das principais estratégias para que a maioria das pessoas se torne consumista e fiel ao mercado consumidor, mas sem a percepção desta condição. E, se percebemos tal condição, ficamos quase sem ação, essencialmente, por dizer que não somos se não consumirmos.

O problema é que a moda "[...] introduz no tempo uma peculiar descontinuidade, que divide segundo a sua atualidade ou inatualidade, o seu estar ou o seu não-estar-mais-na-moda [...]" (AGAMBEN, 2009, p. 66). A influência da moda é constante e, a todo o momento, vai provocando estranhamento e respostas aceite, como forma de não exclusão. E, estranho, aqui se refere àquilo que não está de acordo com as normas e ideais postos, dando a sensação de que não somos. É sempre negação de um eu e proposição de outro eu. Portanto, a moda funciona como um padrão de controle, à medida que lida com imagens ideais que, quando saturadas no seu poder de dispersão ou canalização energética, logo são substituídas por uma nova tendência que chega justamente para fazer as pessoas se adequarem, pensar em e vestirem-se na perspectiva dos apelos, conferindo a sensação de autenticidade. Nesse sentido, um aporte poético: "a Moda que tudo muda nada mais faz do que moldar o desejo de mudar."

É importante destacar que, em meio a este contexto, a dimensão estética e formal da criação, o impulso lúdico, também são cooptados a tornar e a gerar perguntas e respostas insignificantes como se fossem essenciais. Este é um grande exemplo de anestetização dos sentidos, uma vez que provoca grande interferência, demarcação e redemarcação das identidades mediante um constante processo de subjetivação. Assim, podemos dizer que existe uma pseudoarte, um historicismo a indicar o ser 
imerso no contemporâneo como algo essencial, visto que "a obra de arte absorve as experiências cotidianas, a fim de elas fazerem o material de suas próprias experiências reflexionantes." (FLICKINGER 2011, p. 507). E, as artes contemporâneas, fazem-no como forma de fugirem do círculo mágico da determinação filosófica do que se considera verdadeiro, buscando refúgio no cotidiano, naquilo que em sua origem buscavam escapar. Nas palavras de Hermann (2010, p. 43):

A arte autêntica não alivia a dor nem o sofrimento, tampouco
aquieta ou tranquiliza, como em Schopenhauer. Seria muito
menos ainda reduzível a um mero entretenimento. Ela provoca
uma comoção, porque deixa transparecer algo outro que não ela
mesma, que expõe o irreal da realidade. O sofrimento humano
encontra na arte uma forma de expressão, mas não tem a intenção
de evitar a dor, antes, ela dá forças, provoca o calafrio estético.

$\mathrm{O}$ alerta feito por Nadja Hermann diz despeito à pseudoarte, à pseudoexperiência estética, possível de ser percebida por suas finalidades, caindo no círculo mágico que por ora busca denunciar. Por outro, é importante destacar que a arte contemporânea autêntica, aquela que não se perde em si, no círculo mágico, ou no falatório, como diria Heidegger em Ser e Tempo (1995) constitui a necessária redemarcação da própria ideia de filosofia, de reflexão filosófica para a qual "a estética tem se mostrado hábil [...] evidenciando aquilo que é estranho, uma liberdade do sensível contra o embrutecimento da percepção automatizada." (HERMANN, 2011, p. 440). Neste viés, ressaltam-se os propósitos da contemporaneidade do artista e da arte, uma vez que percebemos no artista a liberdade de expressão, justamente quando expõe por meio da arte as mazelas que afetam a formação do ser humano de forma integral, gerando compreensão na temporalidade do acontecer; constituem expressões e chamados à superação do círculo mágico que tudo aprisiona à medida que confere, enganosamente, a ideia de liberdade.

A sociedade contemporânea é uma sociedade fruída em que a arte contemporânea está centrada na ideia de autonomia, ela interage de forma diferente para cada um, pois se configura diferente em si a cada momento. Diante disso, indagamos o conceito de arte contemporânea como uma singularidade que possibilita ao ser humano se experienciar, formar-se como obra de arte em arte, pois "a experiência da arte nos abre um mundo, um horizonte, uma ampliação de nossa autocompreensão, justamente porque ela revela o ser." (HERMANN, 2005, p. 40).

A arte contemporânea guarda singular relação entre o particular e o universal, como o seu tempo, em que o artista expressa sua compreensão da contemporaneidade, questionando o seu tempo. O artista contemporâneo é capaz de criar 
elementos expressivos para representar aspectos do seu meio de uma forma poética, visual, sentimental circunstancialidade, sem padrões prévios, aquele que denuncia, evita e busca ultrapassar o círculo mágico do seu tempo. Ou até ousar causar frente ao posto, como forma de reconhecimento, de saída do anominato como lampejos, clarões na escuridão do seu tempo. Por isso, "o artista contemporâneo nos convoca para um jogo onde as regras não são lineares, mas desdobradas em redes de relações possíveis ou não de serem estabelecidas." (COCCHIARELI, 2006, p. 10). Assim, a arte contemporânea procura novas linguagens ${ }^{6}$, novas formas de expressão condizentes à circunstancialidade do tempo vivido, como conversação que acaba com as noções tradicionais de tempo e de espaço e faz refletir por meio dela as mudanças que vêm ocorrendo na contemporaneidade, ao mesmo tempo que se constitui como elemento de transformação da própria realidade.

Mais do que isso, desprendida do seu sol, a racionalidade, ou valores, padrões universais, agora como em-si, constantemente busca lançar luzes no desafio de continuar iluminando em um iluminar-se a si. Como consequência da autonomia da arte frente a um ideal de beleza e às suas mais diversas incursões, bem como a impossibilidade do seu enquadramento teórico, "a autorreflexividade se tornaria sua marca por excelência, desembocando finalmente na dúvida no que diz respeito à sua própria razão de ser.” (FLICKINGER, 2011, p. 504). Tens que, a partir de si e de seu posicionamento crítico em relação ao mundo, experimentar o impulso reflexivo a ela mesma inerente. Nesse sentido, "ela mesma [a arte] tem de lutar sempre e de novo pelo seu espaço dentro do múltiplo das nossas experiências.” (FLICKINGER, 2011, p. 505). À sua autonomia, pesou-lhe a autorreflexão, a autoformação, a autoexperimentação, efetivando-se como compreensão e autocompreensão. Eis o desafio do próprio homem, do ser humano.

A arte contemporânea nos coloca num jogo em que a obra de arte, enquanto tal e em-si é acontecer, autodemarcação, num contexto em que tudo pode participar constitutivamente da experiência estética, inclusive a própria arte. Vigora uma liberalidade de criação e não mais aquela regra acadêmica que moldava as ideias dos artistas no início da modernidade. A arte não tem mais o propósito de imitar a natureza tal qual ela é, pois ela cria outra realidade com as mesmas e, ao mesmo tempo, estimula a pensar criticamente a realidade em que vivemos e a si. Propõe ser revolucionária e não bem-comportada aparecendo como ser-aí em seu dinamismo. Nesta perspectiva, podemos perceber que, por meio da inter-relação complexa que a obra de arte tem para com a sociedade, a arte contemporânea emerge como o impulso a gerar transformações em configuração. 
Embora a arte contemporânea não se constitua em ideal de beleza universal e não tem projeto estrutural único, está centrada na ideia de autonomia e, por isso, ela dialoga, interage de diferentes formas, como num jogo livre, em que as próprias regras vão sendo ontologicamente desenhadas no momento da produção, precisa minimamente de uma estrutura para ser, mesmo que sua estrutura seja não ter estrutura, seja fruidez. $\mathrm{O}$ artista é "dono de si", no sentido de não ter de prestar contas a um conjunto teleológico de meios e fins definidos. Por tanto, este "dono de si" evidencia a complexidade da experiência estética, como singularidade, visto arte contemporânea guardar íntima relação com a circunstancialidade, uma vez que a arte tem como propósito ressaltar aspectos da sociedade contemporânea. Nesse sentido, a arte grita e expressa, de forma polifônica e polissêmica, aquilo que muitos não conseguem ver e expressar em meio aos conceitos e manipulações de uns sobre outros na sociedade e os deixa passivos, no esquecimento do ser, chamando atenção para a temporalidade humana. É um grito da presença entre tantos outros, por reconhecimento no demarcar e redemarcar dos espaços, das identidades. A arte se torna, desse modo, um meio imprescindível de compreensão, ao existir ético. É a própria compreensão acontecendo em meio às transformações em configuração, à medida que desinstala, conclama o ser para o acontecer.

O belo deixa de ser configurado pelas características transcendentais do objeto quanto do sujeito, para ser transcendentalidade na temporalidade, fenômeno, já que se configura relativo a um tempo, a um contexto, a quem o experiencia. $\mathrm{O}$ belo assume a condição de acontecimento temporal. Liberada em seu modo de ser, a experiência estética constitui-se como o momento originário originante, pelo qual o humano humana, efetiva-se como humanidade. A estética enquanto sensibilidade constitui-se uma dimensão do humano.

Assim, não mais ligada à noção de beleza ou ideal de beleza, a estética, "[...] termo derivado do grego aisthesis, aistheton (sensação, sensível) [que] significa sensação, sensibilidade, percepção pelos sentidos ou conhecimento sensível-sensorial" (HERMANN, 2005, p. 33), agora passa a ser compreendida como fenômeno humano ao jogo de relações indicando a totalidade do acontecer humano como abertura $^{7}$, como singularidade em devir. Assim, a estética é uma faculdade articuladora de entendimento e da sensação na compreensão à medida que em sua totalidade ontológica é constitutiva do ser e de si como abertura como fenômeno. Faculdade da relação pela qual o ser sente e se sente como mundo e a arte contemporânea é o próprio ser-aí: temporalidade, uma vez que "a estética tem se mostrado hábil na experiência da alteridade.” (HERMANN, 2011, p. 440). 
Enfim, caracterizar a obra de arte e a experiência estética contemporânea é algo que ultrapassa os referencias teórico-tradicionais, pois se constituem em perspectivismos os mais diversos, sem acepções e estruturas características universais, talvez universalizantes, visto o seu grande dinamismo e fluidez. Ao que parece, arte contemporânea não se restringe às delimitações tradicionais da contemplação, passando cada vez mais a ser interativa e próxima de nosso cotidiano (TESCH; VERGARA, 2012), como que um reflexo da sociedade com suas preocupações, satisfações, desejos e sentimentos, estando em constante mutação quanto possíveis caracterizações. Isso possibilita indicarmos a experiência estética como vivencial, correndo-se o risco dos modismos. Mas, em meio aos múltiplos modos de ser das elaborações estéticas e das percepções estéticas das obras de arte, indicamos que tais dimensões compõem o fenômeno estético contemporâneo.

\section{EXPERIÊNCIA ESTÉTICA COMO POSSIBILIDADE DE UM ENSINO ÉTICO}

Ao tratar da pluralidade na ética, a estética se interpôs pela sua possibilidade de transcender as fronteiras racionais, criando formas de sensibilidade e experiências de subjetividade que exigem modos de tratamento ético. (HERMANN, 2005, p. 11).

Agora a estética encontra-se autônoma, como um elemento significativo nos processos educativos, na elaboração de novos valores, pela possibilidade de abertura, de configuração de novas perspectivas. Sendo assim, "as possibilidades da estética parecem constituir uma forma produtiva de compreender as novas exigências éticas diante da pluralidade" (HERMANN, 2005, p. 28-29), uma vez que a experiência estética constitui a possibilidade de abertura constitutiva, como experiência da alteridade e não puramente como pluralidade. Diante disso, a emergência da ética vai se estruturar por meio da experiência estética como experiência do diálogo, ou seja, você vai percebendo e compreendendo que precisa de valores para se organizar conforme suas necessidades, com as do seu tempo. Mas que os valores também vão sendo reconfigurados nos horizontes dos acontecimentos. Neste viés a experiência estética possibilita ações plausíveis em que os aspectos sensíveis, cognitivos, afetivos, instintivos formais, o ser humano, em suas multidimensionalidades, colocado em jogo no horizonte das inter-relações se reconfigura, ou é passível de redefinição. Deste Desse modo, na experiência com o outro, seja com o livro, com a obra de arte, com o criar, por meio do diálogo, autoavaliamo-nos, ressignificamo-nos, constitui-se em experiências constitutivas das subjetividades singulares não anuladas pelo univer- 
salismo, tampouco pelo individualismo. Contudo, para que isso ocorra é necessário superar a pura esteticização que anestesia os sentidos e embota a consciência e a pura consciência que embota os sentidos.

Emerge a necessidade de compreender mais detalhadamente as relações íntimas entre estética, ética e formação, problemática esta emergida das respostas dos sujeitos da pesquisa na contraposição com os referenciais abordados no presente estudo. Nesse sentido, o desafio do ensino de Artes na contemporaneidade está justamente em propiciar experiências significativas de alteridade no processo de ensino-aprendizagem, o que possibilitaria o não se perder em devaneios esteticistas, tanto quanto racionalistas e suas derivações.

Refletir sobre experiência estética e formação e seus desafios no viver contemporâneo requer conceber a educação estética para além da ideia de verdade absoluta e puramente racional ou do puramente sensível, da distinção estética que profundamente perpassou, estruturou o paradigma ocidental até a ruptura da metafísica e ainda continua visível na medida da permanência do círculo mágico ${ }^{8}$ (FLICKINGER, 2011) que ora perpassa a arte contemporânea, quando busca refúgio no cotidiano, a exemplo da moda.

Hermann (2014, p. 24) coloca que "[...] a experiência estética atua sobre nossas rígidas estruturas de apropriação, articula-se com as emoções, desvela o estranho e possibilita que o outro aconteça." Já “o diálogo, rompe com a lógica de apropriação, pois só se institui porque há um outro, o que supõe a disponibilidade de rever nossa base de valoração questionada pela posição do outro.” (HERMANN, 2014, p. 24).

Nesse texto, exploramos a relação entre experiência estética e formação no horizonte da ética em que a experiência estética se constitui possibilidade ao acontecer ético, pois como possibilidade de abertura das estruturas rígidas, efetiva-se possibilidade do diálogo, podendo o humano se efetivar como humano pelo jogo intersubjetivo. Portanto, como possibilidade de transformação em configuração em se encontrar como o outro, como se autocriar.

Citando Welsch (1995), Hermann (2005, p. 54) sinaliza que nem toda a estetização ou experiência estética significa algo melhor e indica que a experiência estética precisa ultrapassar o círculo mágico de reificação da violência, a distinção estética, como sinaliza Gadamer (2005), visto que onde tudo é belo nada mais é belo, caindo num circo de horrores. E estetização vira anestização (WELSCH, 1995). Experiência estética como experiência ética possibilita ultrapassar não somente a esteticização, mas a moral como dispositivos de controle. Assim, à medida que "[...] a experiência estética traz o estranho, a inovação e a pluralidade que não podem ser 
desconsiderados no plano da interpretação e problematização do agir moral" (HERMANN, 2005, p. 29), os processos de ensino e de aprendizagem como experiência estética são vistos como momento do acontecer originário originante tanto das subjetividades postas em jogo quanto da própria subjetividade o processo, ou seja, os fins, os meios e as articulações entre meios e fins, sem que "[...] a educação abandone critérios éticos [...]" (HERMANN, 2005, p. 28) ou deixe de orientar-se pela ideia de bem. "A estética aponta [...] que a educação não é possível sem um ethos da diferença e da pluralidade." (HERMANN, 2005, p. 109). Por isso, é preciso o livre jogo em que o ser vá se efetivando enquanto ser livre, mas orientado por uma conduta dialógica, visto que é no acontecer do diálogo que o sentido surge (GADAMER, 2005).

\section{CONSIDERAÇÕES FINAIS}

Historicamente, tanto a arte, a estética, a experiência estética e a relação, quanto a formação, estiveram orientadas pelo ideal de homem racional, aquele capaz de subordinar seus instintos e paixões à razão, de, por fim, agir com base na razão. Este ideal de homem institui-se com os gregos como um dos principais elementos estruturadores da cultura ocidental e permaneceu intocado em sua estrutura básica até a crise da modernidade, quando emerge o paradigma estético como uma alternativa, recolocando o problema da temporalidade pelo viés do cotidiano, da contingência, caindo facilmente na esteticização. A experiência estética fica empobrecida, pois é compreendida unilateralizada, ou no sujeito ou no objeto, colocada em segundo plano. É compreendida como experimento ou como pura vivência e não enquanto livre jogo. Isso permite afirmar que, até então, na estética clássica e na estética moderna, a estética esteve orientada por e para este paradigma racional, configurada como distinção estética em que, respectivamente, a percepção, ou dependia das qualidades do objeto, ou do sujeito, uma vez que pautada por referenciais transcendentais unilateralizados. Em termos éticos, a ação educativa esteve orientada por e para ideais prévios.

Com a crise da modernidade a estética emerge como paradigma autônomo, faculdade da relação pela qual o ser sente e se sente como mundo, como abertura, como ser em devir, à medida que traz o estranho, a inovação e a pluralidade e o desafio à recriação dos valores referenciais. Nesse contexto, a experiência estética "[...] tem se mostrado hábil na experiência da alteridade" (HERMANN, 2011, p. 440), possibilitando a educação como um acontecer originário originante, sem que "[...] a educação abandone critérios éticos [...]" (HERMANN, 2005, p. 28). 
No contemporâneo, a obra de arte possui valor em si e como presença (GADAMER, 2005), devir, sendo, ao mesmo tempo, em-si e energia. É acontecimento, temporalidade, por isso, a própria arte precisa lidar sempre de novo com o seu próprio impulso, numa constante redefinição de si, para si, a partir de si. Por fim, sua autonomia pesou-lhe a autorreflexão, a autoformação, a autoexperimentação efetivando-se como compreensão e autocompreensão. Eis o desafio do próprio homem, do ser humano.

Entretanto, diante do pluralismo ético que vivenciamos na contemporaneidade e das questões colocadas pelo universalismo ético, percebemos as dificuldades de se estabelecer o diálogo intersubjetivo. O desafio está em aprender a relacionar-se com as diferenças, na experiência profunda de si e do outro (seja enquanto outro, obra de arte, livro etc.), como compreensão do outro, como bases do agir moral.

Enfim, a experiência estética constitui-se em acontecimento formativo ético, uma vez que questiona e ultrapassa os processos de anestetização, o próprio círculo mágico de reificação - a distinção estética -, e institui-se como experiência dialógica. Isso implica que não é qualquer acontecimento estético que se configura como acontecimento formativo ético, senão os que especialmente se efetivam como experiência de alteridade, de experiência de alteridade. $\mathrm{O}$ reconhecimento da radicalidade da autonomia da estética enquanto experiência formadora nos processos educativos implica nova configuração do sistema educacional capaz de assumir, nos processos de ensino, não apenas de Artes, o papel que a estética vem protagonizando enquanto protagonista da abertura ao outro, do outro enquanto diálogo, pois é no acontecer do diálogo que o sentido surge.

Notas explicativas:

${ }^{1}$ Informamos que a identificação dos relatos dos professores trazidos aqui segue a lógica de apresentação presente no relatório de pesquisa que nomeia os professores com as letras do alfabeto, por isso PF. A pesquisa A compreensão dos professores da educação básica que atuam no ensino de artes na região de abrangência da Secretaria de Desenvolvimento Regional de São Miguel do Oeste quanto à relação entre experiência estética e formação, foi desenvolvida na Unoesc/SMO, com apoio do PIBIC/CNPq, conforme o edital interno N. 19 UNOESC-R/2012, sendo que o mesmo se encontra disponível na biblioteca desta IES.

${ }^{2}$ Conversando com Jayme Paviani - Entrevista concedida por Jayme Paviani a Luiz Carlos Bombassaro e Evaldo Antonio Kuiava, por ocasião da publicação do livro homenagem Pensar Sensível organizado por Luiz Carlos Bombassaro, Claudio Almir Dalbosco e Evaldo Antonio Kuiava e publicado pela EDUCS em 2011.

${ }^{3}$ As compreensões de experiência estética em Platão e em Aristóteles, seja como pura representação ou como exercício mimético produtivo, lançam referências que merecem atenção quando do estudo da relação entre experiência estética e formação contemporânea. Platão em especial por sua referência ao problema da esteticização do mundo da vida apontado por Welsch (1995); Aristóteles quanto à experiência mimética produtiva. Ambos no que se refere à compreensão da condição humana como temporalidade: o primeiro quanto à linguagem e o segundo quanto à compreensão de indivíduo enquanto energia.

4 “"[...] significa que algo se torna uma outra coisa, de uma só vez e como um todo, de maneira que essa outra coisa em que se transformou passa a constituir o seu verdadeiro ser, em face do qual o seu ser anterior é nulo. [...] significa que aquilo que era antes não é mais." (GADAMER, 2005, p. 166). 


\begin{abstract}
${ }^{5}$ Oliveira (2011, p. 413) referindo-se à Verdade e Método indica que “[...] a compreensão não é entendida apenas como uma forma e comportamento do sujeito diante de um objeto dado, mas como uma dimensão constitutiva do próprio ser do eis-aí ser (DASEIN)."

6 "[...] a linguagem é o lugar da abertura permanente [...] o mundo é sempre linguisticamente experienciado [...] ela articula todo o âmbito de nossa experiência" (OLIVEIRA, 2011, p. 214-415), visto que "[...] a linguagem não pertence propriamente à esfera do $e u$, mas à esfera do nós, ou melhor ainda, à esfera que une eu e nós, nós e mundo" (OLIVEIRA, 2011, p. 417).

7 “A abertura é [...] a estrutura primária do Dasein o que significa dizer que nós já sempre nos movemos na compreensão do ser.” (OLIVEIRA, 2011, p. 428).

8 "O problema das artes atuais perderem completamente de vista o que elas devem à teoria, mas também ao desamparo mostrado pela teoria diante de obras de artes não mais acessíveis por meio do esforço terminológico, não alimentam grande esperança de poder reconstruir uma ponte nova entre os dois campos de experiência. Parece que essa situação precária se deve a uma tendência dupla e aparentemente indiferente quanto a qualquer pretensão de verdade. Ao fugir do círculo mágico da determinação filosófica do que se considera verdadeiro, as artes contemporâneas vêm buscando refúgio no cotidiano, do qual elas, na sua origem tentam escapar." (FLICKINGER, 2011, p. 507).
\end{abstract}

\title{
REFERÊNCIAS
}

AGAMBEN, G. O que é contemporâneo? e outros ensaios. Tradução Vinícios Nicastro Honesko. Chapecó: Argos, 2009. 92 p.

BARBOSA, A. M. Arte/Educação contemporânea: consonâncias internacionais. São Paulo: Cortez, 2006. 432 p.

BAYER, R. História da estética. Lisboa: Estampa, 1995. 459 p.

BAUMANN, Z. Modernidade líquida. Tradução Plínio Dentzein. Rio de Janeiro: Jorge Zahar Editor, 2001.

BOMBASSARO, L. C.; DALBOSCO, C. A.; KUIAVA, E. A. Pensar sensível. Caxias do Sul: EDUCS, 2011.

COCCHIARALE, F. Quem tem medo de Arte Contemporânea? Recife: Fundação Joaquim Nabuco; Massangana, 2006. 74p.

FLICKINGER, Hans-Georg. Deslocamento da fronteira ente filosofia e artes. In: BOMBASSARO, L. C.; DALBOSCO, C. A.; KUIAVA, E. A. Pensar sensível. Caxias do Sul: EDUCS, 2011. p. 497-509.

GADAMER, H-G. Verdade e método I: traços fundamentais de uma hermenêutica filosófica. 7. ed. Petrópolis: Vozes; São Paulo: Ed. Universitária São Francisco, 2005 .

GADAMER. Verdade e método II: complemento e índice. 2. ed., Petrópolis: Vozes; São Paulo: Editora Universitária São Francisco, 2004. 
GOERGEN, P. O embate da modernidade/pós-modernidade e seu impacto sobre a teoria e a prática educacional. Eccos - Revista Científica, São Paulo, n. 28, p. 149169, maio/ago. 2012.

HABERMAS. J. O discurso filosófico da modernidade. São Paulo: Martins Fontes, 2002.

HERMANN, N. Ética e estética: a relação quase esquecida. Porto Alegre: Edipucrs, 2005, 119 p. (Coleção filosofia; 193).

HERMANN. Autocriação e horizonte comum: ensaios sobre a educação ético-estética. Ijuí: Ed. Unijuí, 2010.

HERMANN. O outro na intersubjetividade. In: BOMBASSARO, L. C.; DALBOSCO, C. A.; KUIAVA, E. A. Pensar sensível. Caxias do Sul: EDUCS, 2011. p. 433-443.

HERMANN. Educação \& ética: outra sensibilidade. Belo Horizonte: Autêntica, 2014.

HEIDEGGER, M. Ser e tempo. Tradução Márcia de Sá Cavalcante. Petrópolis: Vozes, 1995.

HEIDEGGER. A origem da obra de arte. Tradução Idalina Azevedo e Manuel António de Castro. São Paulo: Edições 70, 2010.

JIMENEZ, M. O que é estética? Tradução Fulvia M. L. Moretto. São Leopoldo: Ed. Unisinos, 2000. $413 \mathrm{p}$.

KANT, I. Fundamentação da metafísica dos costumes e outros escritos. São Paulo: Marin Claret, 2003.

KANT. Crítica da faculdade do juízo. Traduzido da 2. ed. alemã de 1793, por Valério Rohden e Antonio Marques. Rio de Janeiro: Forense Universitária, 2008.

LAGO, C. Experiência estética e formação: articulação a partir de Hans-Georg Gadamer. 2011. 121f. Tese (Doutorado em Educação)-Pontifícia Universidade Católica do Rio Grande do Sul, Porto Alegre, 2011.

LAGO. Experiência estética como experiência formativa a partir da ontologia de Hans-Georg Gadamer. EccoS - Revista Científica, São Paulo, n. 28, p. 17-30, maio/ ago. 2012. 
LONGHI, A. J. O artista fingidor: o conceito de mimese em Platão. Ágora, Caçador/Canoinhas/Concórdia/Curitibanos/Mafra (SC), v. 12, n. 2, p. 393-409, jul./dez. 2005.

LYOTARD. J-F. O pós-moderno. Tradução Ricardo Correia Barbosa, Rio de Janeiro: Olympio, 1993.

LYPOVETSKY, G.; CHARLES, S. Os tempos hipermodernos. São Paulo: Barcarolla, 2004.

MEDEIROS, M. B. de. Aisthesis: estética, educação e comunidades. Chapecó: Argos, 2005. 185 p.

OLIVERIA, M. A. de. Hermenêutica e culturas: a problemática da relação entre filosofia e culturas. In: BOMBASSARO, Luiz Carlos; DALBOSCO, Claudio Almir; KUIAVA, E. A. Pensar sensível. Caxias do Sul: EDUCS, 2011.

OURIQUE, M. L. H.; TREVISAN, A. L. Educação, formação cultural e pluralidade de perspectivas entre outros (em)cantos das sereias. Disponível em: $<$ http:// www.anped.org.br/reunioes/30ra/trabalhos/GT17-3095--Int.pdf $>$. Acesso em: 11 jan. 2011. Trabalho apresentado na 30a Reunião Anual da Anped, Caxambu/MG, 2007.

SCHILLER, F. Cartas sobre a educação estética da humanidade. Introdução e notas de Anatol Rosenfeld. São Paulo: EPU, 1991.

TESCH, J. C.; VERGARA, C. Arte contemporânea no espaço escolar. Anais da IX ANPED SUL, 2012.

TREVISAN, A. L. Filosofia da educação: mímesis e razão comunicativa. Ijuí: Ed. Unijuí, 2000.

WELSCH, W. Esteticização e esteticização profunda: ou a respeito da atualidade do estético nos dias de hoje. Tradução de Alvaro Reis. Porto Alegre, Porto Alegre, v. 6, n. 9, p. 7-22, maio 1995 .

Recebido em: 29 de março de 2015

Aceito em: 28 de setembro de 2015

Endereço para correspondência: Rua Getúlio Vargas, 2125, Flor da Serra, 89600000, Joaçaba, Santa Catarina, Brasil; cleniolago@yahoo.com.br 
